\title{
Regulación y calidad de los servicios públicos liberalizados
}

Antón Costas

Palabras clave: Servicios públicos, liberalización, calidad de los servicios públicos, evaluación.

\section{La calidad de los servicios públicos de red: ¿el coste oculto de la liberalización? ${ }^{1}$}

Las industrias de servicios en general, incluyendo la banca y los servicios financieros, seguros, servicios profesionales, pensiones, sanidad y servicios públicos domiciliarios, han estado sometidas en los últimos años a un generalizado proceso de liberalización. Este proceso ha sido especialmente intenso en el caso de las industrias de servicios públicos de red (public utilities): telecomunicaciones, electricidad, gas, agua, transporte y servicios postales. En esencia, la liberalización ha buscado introducir mayor eficiencia en la prestación de estos servicios a través del aumento de la competencia entre proveedores, en un proceso que ha ido acompañado en muchos países de la privatización de los antiguos monopolios públicos y que, implícitamente, prometía un cambio en la estructura de oferta, un incremento de la competencia entre proveedores, el fomento de la eficiencia de los operadores, una reducción generalizada de los precios y el desarrollo de la calidad de los servicios de las empresas.

Hasta ahora la prioridad de los reguladores europeos, tanto comunitarios como nacionales, ha estado centrada fundamentalmente en promover la competencia, la eficiencia y las reducciones de precios. Para ello, la regulación de precios ha cambiado en muchos casos del método de regulación de la tasa de beneficio a la regulación mediante sistemas de precios máximo (price-cap). Un cambio que ha tenido dos objetivos: por un lado, permitir a las empresas una mayor flexibilidad a la hora de decidir sus inversiones en infraestructura y en su funcionamiento; y por otro, permitir a las autoridades reguladores presionar a la baja de precios?

\footnotetext{
" Catedrático de Política Económica de la Universidad de Barcelona. Director del Grupo de Investigación en Políticas Públicas y Regulación Económica y del Master en Economía y Regulación de los Servicios Públicos de la citada Universidad.

${ }^{1}$ Una versión de este estudio se publica paralelamente en la colección de documentos de trabajo que edita la Agencia Estatal de Evaluación de Políticas y Servicios Públicos. El autor agradece a Monserrat Martín y Paloma Mirada la ayuda prestada en la recopilación y tratamiento de la documentación utilizada en este trabajo, especialmente la relativa a la Unión Europea y al seguimiento de lo que en el terreno de la calidad del servicio están realizando empresas y reguladores nacionales de sus diferentes países.

${ }^{2}$ Una forma de comprobar que estas están siendo las prioridades de los reguladores es analizar los indicadores de éxito que con más frecuencia han manejado los policy makers y los reguladores europeos en sus evaluaciones y benchmarkings de resultados de la liberalización, tanto ver-
} 
Esta prioridad hacia los objetivos relacionados con la competencia, la eficiencia y los precios ha relegado la atención sobre otro aspecto esencial: la calidad del servicio. Sin embargo, existen muchas razones, tanto teóricas como empíricas, para prestar atención a la problemática relacionada con la calidad de los servicios liberalizados. De hecho, hay evidencia de que las empresas pueden tender a aumentar sus ingresos y reducir costes de inversión y operativos en detrimento de la calidad del servicio, especialmente en el intervalo de tiempo que transcurre entre dos períodos de regulación de precios.

Por otra parte, era de esperar que la liberalización impactase de forma directa sobre algunos de las dimensiones de la calidad del servicio de sectores de las industrias de red. Así, en la medida en que la liberalización da lugar a la desaparición de las subvenciones cruzadas que se hacían dentro del antiguo monopolio entre servicios o actividades deficitarias y actividades excedentarias, cabía esperar que algunas de esas actividades deficitarias dejasen de prestarse por el operador dominante en el momento en que entrasen a competir nuevos operadores. De hecho, este problema se ha presentado en la mayor parte de los servicios de las industrias de red liberalizadas, desde el transporte aéreo o por ferrocarril pasando por los servicios postales y las telecomunicaciones. En este sentido, la existencia o no de un servicio y la frecuencia con la que es prestado por los proveedores constituye una de las dimensiones fundamentales de la calidad del servicio.

Asimismo, cabía esperar también que algunos grupos sociales de rentas bajas o zonas geográficas alejadas pudiesen resultar perjudicados por el proceso liberalizador, especialmente en el caso de nuevos servicios de valor añadido -como, por ejemplo, el acceso a Internet-, tan importantes para la condición de ciudadanía moderna y para el desarrollo económico de los territorios.

De hecho, esta preocupación por los efectos de la liberalización sobre la calidad de algunos servicios ha llevado a los policy-makers y a los reguladores a definir determinadas obligaciones de servicio público en todas las industrias de servicios de red (telecomunicaciones, electricidad, gas, agua, transporte y servicios postales). En general, estas obligaciones de servicio público se vinculan con una serie de objetivos como son la universalidad en el acceso, la asequibilidad del precio y la calidad del servicio. Este último, ya sea de forma directa o vinculado a los otros objetivos, constituye un componente expansivo de las obligaciones de servicio público incorporadas a los ahora llamados «servicios de interés general», etiqueta con la que la Comisión Europea define a las industrias de servicios públicos de red a partir de la liberalización ${ }^{3}$.

Pero más allá de estas obligaciones de servicio público, la calidad del servicio no ha sido una prioridad para los reguladores comunitarios. Este «olvido» quizá haya sido debido a que se esperaba que en el nuevo entorno competitivo en el que se iban a mover estas industrias los mecanismos de mercado serían suficientes para que las empresas suministrasen niveles de calidad del servicio acordes con las preferencias y la disposición a pagar de los consumidores. Uno de esos mecanismos de mercado que se esperaba que presionara en favor de la calidad era la opción de «salida», es decir, la posibilidad de los consumidores de elegir, en un entorno liberalizado, entre distintos proveedores, frente a la situación de cautividad en la que se encontraban anteriormente cuando un único proveedor monopolizaba el sector.

La nueva posición del consumidor en ese nuevo escenario de mercado más procompetitivo quedó reflejada en la propia terminología utilizada para referirse al usuario de estos servicios: de la vieja condición de «abona-

\footnotetext{
ticales como horizontales, y que hasta ahora ha venido manejando la Comisión Europea (Comisión Europea 2002, 2004 y 2005). En el Anexo 2 de este trabajo se resumen los indicadores de resultados utilizados en la metodología que viene siguiendo la Comisión Europea para la evaluación horizontal de servicios de servicios de interés general desde el año 2002.

${ }^{3}$ Véase el Anexo 2, donde se resumen las nuevas obligaciones de servicio público incorporadas por la Unión Europea tras el proceso de liberalización.
} 
do» que tenía en el régimen de monopolio pasó a la de «cliente», subrayando su opción de penalizar la mala calidad del servicio cambiando de empresa suministradora.

Adicionalmente, los reguladores recomendaron a las propias empresas implementar mecanismos de autorregulación de la calidad del servicio. De ahí que en muchos países, especialmente del área anglosajona, las autoridades hayan recomendado la autoregulación de la calidad mediante la implantación de códigos de conducta, cartas de compromiso con los clientes, creación de figuras como la del «defensor del cliente», o el adherirse a sistemas de arbitraje voluntarios para la mediación de conflictos.

Sin embargo, en los últimos años se ha ido acumulando evidencias suficientes, tanto teórica como empírica, que cuestionan la capacidad de los mecanismos del mercado y de la autorregulación para introducir incentivos adecuados que fuercen a las empresas a suministrar niveles de calidad óptima, acordes con las preferencias de los consumidores.

Primero, existen suficientes evidencias teóricas de que sin una adecuada regulación de la calidad del servicio la regulación de precios puede dar a las empresas incentivos distorsionados para inversiones en infraestructuras y gestión de los servicios (Baldwin y Cave 1999). Así, si la regulación de la tasa de beneficio de las empresas fomenta una excesiva inversión en capital la calidad del servicio puede estar por encima de lo que están dispuestos a pagar los consumidores. Por el contrario, bajo un sistema de regulación de precios máximos (price-cap), las empresas pueden tener incentivos para reducir costes en inversiones y sistemas operativos que afecten a la calidad del servicio.

Y segundo, hay también evidencias que demuestran que los mecanismos de autorregulación de la calidad por parte de las propias empresas, si bien pueden llegar a crear en el mejor de los casos incentivos ambiguos para la mejora de la calidad, por lo general acaban por manifestar una inconsistencia temporal, al estar afectados por contingencias y estrategias derivadas de los objetivos de las empresas.

La evidencia empírica acerca del deterioro de la calidad es también cada vez más abundante en aspectos relacionados con la calidad comercial y la calidad de atención. Las reclamaciones por fraude, negligencia y, en general, por malas prácticas relacionadas con la calidad del servicio están creciendo de forma significativa, especialmente en algunos servicios como el de las telecomunicaciones o el transporte aéreo. En esta última industria la multiplicación de compañías ha hecho surgir nuevas formas de competencia en precios que parece estar provocando una deterioro importante de la calidad del servicio, más allá de límite en el que los clientes no estarían dispuestos a aceptar si tuviesen una información adecuada de las consecuencias que puede tener sobre la seguridad del servicio.

Por lo tanto, en un primer balance, la calidad del servicio emerge como el coste olvidado de la liberalización. De aquí que los reguladores están prestando una atención creciente a este resultado y se afanen en buscar mecanismos adecuados para integrar la calidad dentro de los sistemas de incentivos que se utilizan para fomentar el comportamiento eficiente de las empresas. El objetivo último de una buena regulación es lograr una calidad del servicio adecuadamente alineada con las preferencias de los consumidores.

A continuación se examinarán, en primer lugar, algunos de los complejos problemas que surgen a la hora de definir el contenido de «calidad de servicio» en las industrias de red. En segundo lugar se pasará a analizar los enfoques utilizados para ajustar la calidad del servicio a las preferencias de los consumidores. En tercer lugar, se hará referencia a los mecanismos utilizados con más frecuencia por los reguladores para reducir el problema de la información asimétrica y para integrar la calidad del servicio en los esquemas de incentivos. En cuarto lugar, se defenderá a la necesidad de implementar una estructura institucionalizada para desarrollar un proceso sistemático de evaluación de la calidad, para, por último, concluir con una defensa de la evaluación de la calidad. 


\section{2. ¿A qué llamamos calidad del servicio?}

La «calidad del servicio» de una industria de servicios públicos de red se refiere tanto a los atributos específicos del producto que suministran al consumidor final (la «calidad de onda» en el caso de la electricidad), como a una serie de actividades de tipo técnico (nuevos suministros o accesos a la red, por ejemplo), comerciales (proceso de lectura, facturación y cobro) o de atención al cliente (reclamaciones e información), actividades todas ellas que son previas o posteriores a la provisión del servicio. Por lo tanto, la calidad del servicio en estas industrias está relacionada tanto con las instalaciones de producción como con las redes a través de las cuales se suministra el servicio al cliente (infraestructuras o hardware y sistemas o software), y con los procesos comerciales y de atención al cliente que utilizan las empresas.

De acuerdo con esta primera definición, podemos identificar tres grandes dimensiones de la calidad:

- Calidad del producto

- Calidad comercial

- Calidad de atención

Los aspectos referidos a la calidad del producto acostumbran a ser específicos de cada industria. Se relacionan, en general, con aspectos o atributos técnicos del producto (electricidad, gas, servicio telefónico, etc.), y acostumbran a ser objetivamente cuantificables con las tecnologías de medición actualmente existentes. Normalmente constituyen el núcleo de los indicadores de gestión que manejan las empresas a la hora de medir e incorporar la calidad a sus procedimientos y objetivos empresariales.

Por el contrario, los aspectos relacionados con la calidad comercial y con la calidad de atención son comunes a la mayoría de industrias de red (telecomunicaciones, electricidad, gas, agua, correos y transportes). La calidad comercial se refiere a aspectos tales como las condiciones contractuales, la libertad para escoger el modo de pago, el tiempo de instalación o conexión, y otros como la eficiencia de los procesos de lectura, facturación y cobro, las garantías que se dan a los clientes o la fiabilidad del suministro. Este tipo de atributos acostumbran también con frecuencia a formar parte de los indicadores de gestión de calidad que utilizan las empresas.

La calidad de atención al cliente se relaciona con la existencia de procedimientos transparentes, sencillos y poco onerosos para tramitar reclamaciones:ofrecer información sobre tarifas tiempo, mejorar la información que se suministra a los clientes y el tipo de atención que se presta a sus reclamaciones y, en general, todo aquello que tiene que ver con las preferencias de los consumidores. Este tipo de atributos o variables de la calidad del servicio tradicionalmente no acostumbraban a formar parte del cuadro de indicadores de gestión de las empresas en la fase del monopolio del servicio.

En términos generales las dimensiones que con mayor frecuencia son objeto de algún tipo de regulación son las técnicas y las comerciales. Estos indicadores acostumbran a ser utilizados por las empresas como indicadores de gestión objetiva de la calidad del servicio. Sin embargo, de forma creciente, el interés por la calidad del servicio se está desplazando hacia atributos más cualitativos, relacionados con la atención al cliente y las percepciones sobre la calidad del servicio de los consumidores (Tabla 1). 


\section{TABLA 1}

Indicadores de calidad más frecuentes en las industrias de servicios de red

\begin{tabular}{|c|c|c|}
\hline & Indicadores de calidad regulados & Indicadores de calidad no regulados \\
\hline \multirow[t]{4}{*}{$\begin{array}{l}\text { Variables } \\
\text { cuantificables o } \\
\text { técnicas }\end{array}$} & $\begin{array}{l}\text { Sector energético } \\
\text { - Tiempo y número de interrupciones equivalentes a la } \\
\text { potencia instalada en media tensión (TIEPI y NIEPI). } \\
\text { - Procedimiento interrupciones programadas. } \\
\text { - Límite máximo de variación de tensión y frecuencia } \\
\text { de la tensión suministrada. (En España, regulado a } \\
\text { través de la norma UNE-EN } 50160 \text { y las ITC } \\
\text { dictadas por el MINECO). } \\
\text { - Plazo de elaboración presupuestos para nuevos } \\
\text { suministros. } \\
\text { - Plazo de ejecución de instalaciones para nuevos } \\
\text { suministros. } \\
\text { - Plazo de instalación del equipo medida. } \\
\text { - Atención reclamaciones sobre medida consumo, } \\
\text { facturas, cortes indebidos. } \\
\text { - Enganche después de corte por impago. } \\
\text { - Ejecución indebida por corte por impago. } \\
\text { - Porcentaje de fuentes de energía renovables respecto } \\
\text { del consumo total de electricidad, o respecto del total } \\
\text { de electricidad generada. } \\
\text { - Seguridad del suministro. }\end{array}$ & $\begin{array}{l}\text { Sector energético } \\
\text { - Interrupciones imprevistas de menos de } 3 \text { minutos. } \\
\text { - Calidad de onda a nivel individual. (En la actualidad, el } \\
\text { cliente puede instalar, a su cargo, un sistema de registro } \\
\text { de medida de incidencias). }\end{array}$ \\
\hline & $\begin{array}{l}\text { Sector telecomunicaciones } \\
\text { - Plazo de suministro de la conexión inicial. } \\
\text { - Plazo de reparación de averías. } \\
\text { - Proporción de averías por línea de acceso. } \\
\text { - Demora de establecimiento de llamada. } \\
\text { - Tiempo de respuesta para diversos servicios de la } \\
\text { operadora. } \\
\text { - Porcentaje de cabinas telefónicas en funcionamiento. } \\
\text { - Reclamaciones sobre facturación. }\end{array}$ & \\
\hline & $\begin{array}{l}\text { Servicios postales } \\
\text { - Mínimo de una recogida o una distribución a } \\
\text { domicilio todos los días laborables, y por lo menos } 5 \\
\text { días por semana, excepto en condiciones } \\
\text { excepcionales. } \\
\text { - Número de oficinas de correos por cada x habitantes. } \\
\text { - Número de buzones por cada x habitantes. }\end{array}$ & \\
\hline & $\begin{array}{l}\text { Transporte público terrestre } \\
\text { - Número de accidentes respecto a la distancia } \\
\text { y/o los pasajeros. } \\
\text { - Frecuencia, velocidad y puntualidad. }\end{array}$ & \\
\hline
\end{tabular}




\section{TABLA 1 (Continuación)}

\section{Indicadores de calidad más frecuentes en las industrias de servicios de red}

\begin{tabular}{|c|c|c|}
\hline & Sector energético & Sector energético \\
\hline \multirow{2}{*}{$\begin{array}{l}\text { Variables } \\
\text { cualitativas o de } \\
\text { atención al cliente }\end{array}$} & $\begin{array}{l}\text { - Informar y asesorar a los clientes sobre la tarifa y la } \\
\text { potencia más adecuadas a sus necesidades. }\end{array}$ & $\begin{array}{l}\text { - Citas programadas con el cliente. } \\
\text { - Atención de reclamaciones sobre calidad del servicio. }\end{array}$ \\
\hline & $\begin{array}{l}\text { Resto de sectores } \\
\text { - Condiciones contractuales transparentes. } \\
\text { - No abonar cargo alguno por cambiar de } \\
\text { suministrador. }\end{array}$ & $\begin{array}{l}\text { Resto de sectores } \\
\text { - Evaluación de dificultades para cambiar de empresa } \\
\text { suministradora de servicios. } \\
\text { - Libertad para elegir el método de pago. } \\
\text { - Indicadores generalizados acerca de la resolución de } \\
\text { conflictos. }\end{array}$ \\
\hline
\end{tabular}

Fuente: Elaboración propia a partir de análisis de las regulaciones sectoriales de diferentes países.

De hecho, en un entorno competitivo como el que se mueven ahora estas industrias, la calidad debería relacionarse con aquellos atributos o dimensiones que son más valoradas por los clientes. De nada vale los atributos técnicos o comerciales de un producto o servicio sino son apreciados por el consumidor. Así, por ejemplo, algunos estudios de calidad percibida señalan que en el caso de una interrupción del suministro los consumidores valoran igual o en mayor medida una información adecuada por parte de la empresa sobre el tiempo que durará la interrupción que el esfuerzo de la empresas para reducir ese tiempo a la mitad (Endesa 2004). Este hecho es relevante, dado que los esfuerzos y las inversiones de las empresas suelen ir dirigidos a reducir el tiempo de interrupción más que a informar de forma fiable a los clientes.

Podemos concluir que la calidad del servicio es un concepto multidimensional, que contiene dentro de si muchos atributos o dimensiones. El hecho de que a menudo muchos de esos atributos o dimensiones no son observables directamente por el consumidor y, por lo tanto, tampoco son medibles por parte de las autoridades reguladoras, añade una complejidad adicional. Y aun incluso aquellas dimensiones de la calidad que son observables por los consumidores presentan dificultades añadidas por el hecho de que a menudo el nivel de calidad de esos atributos varía con las preferencias de los consumidores y que esas preferencias cambian mucho de unos grupos de consumidores a otros.

En cualquier caso, lo que acabo de señalar apunta a la importancia creciente que tiene el conocer las preferencias de los consumidores y la necesidad por parte de las empresas y los reguladores de elaborar mecanismos de información (encuestas) sobre calidad percibida, que puedan ser utilizadas para identificar medidas cualitativas de calidad y para diseñar incentivos que introduzcan estas medidas cualitativas en los sistemas de incentivos para las empresas.

Existen al menos dos motivos adicionales por los cuales los reguladores y las empresas experimentarán de forma creciente la necesidad de conocer mejor las preferencias de los consumidores y la necesidad de realizar encuestas de calidad percibida. Por un lado, porque el progreso técnico en este tipo de industrias está incorporando complejidad y sofisticación creciente a los servicios que suministran. Por otro, porque las preferencias y necesidades de los consumidores se hacen más sofisticadas y complejas al incorporar algún tipo de interés por las características del proceso productivo de los productos y por los efectos sobre el medioambiente («energía verde», en la industria eléctrica), o la seguridad y efectos sobre la salud (las antenas de la telefonía móvil). 
Esta tendencia a la complejidad y sofisticación de los servicios agrega nuevas dimensiones de «calidad» a los productos y servicios de estas industrias. Pero cualquiera de estas dimensiones de la calidad sólo pueden de forma indirecta relacionarse con la calidad global o servicio. Esto puede provocar, como se verá más adelante, que en la elección de las medidas concretas de calidad por parte de los reguladores induzcan incentivos distorsionados a los productores, de tal forma que les lleve a concentrarse prioritariamente en las dimensiones observables de la calidad a expensas de aquellas otras no observables pero de interés para los consumidores.

Así pues, la elección de los parámetros más adecuados para conocer la calidad del servicio se complica cuando tomamos en consideración las múltiples dimensiones que integran la calidad global. Pero estas no son las únicas razones que hacen difícil el proceso de seleccionar y medir la calidad del servicio de estas industrias. Existen otras consideraciones adicionales que complican esta tarea.

La calidad del servicio de estas industrias está afectada con frecuencia por contingencias imprevisibles que hacen que a menudo sea difícil distinguir si la mala calidad está originada por negligencia o malas prácticas del proveedor, si es consecuencia de factores externos no controlados por la empresa oferente (causas de «fuerza mayor») o si es el resultado de la acción de terceros sobre las redes de distribución de las empresas. Por ejemplo, en el actual sistema liberalizado -con segmentación de actividades de generación, transporte, distribución y comercialización- es difícil discernir los problemas de calidad del distribuidor o prestador del servicio final de los problemas derivados de la falta de calidad del transportista o carrier. En estas circunstancias, las empresas que suministran el servicio final pueden tender a dar un nivel de calidad inferior al que maximiza el bienestar, porque no pueden capturar el beneficio total que se deriva de sus esfuerzos por mejorar la calidad del servicio que suministran.

Como ha señalado Sappington (2005), este problema es muy acusado en las industrias de red. En estas industrias el nivel de calidad del servicio que recibe un cliente depende tanto de la calidad suministrada por el operador al que el cliente está vinculado contractualmente como a la calidad suministrada por otras redes. Por ejemplo, cuando un cliente de la red de telecomunicaciones A llama a un cliente de la red de telecomunicaciones B, la calidad de la llamada a menudo dependerá de la calidad de ambas redes. Por lo tanto, el cliente de A se beneficiará cuando la red de B mejore. Pero esto puede hacer que A y B suministren un nivel de calidad inferior al que maximizaría el bienestar del cliente. Este mismo problema se plantea en la mayoría de las industrias de red que han sido liberalizadas.

Todas estas complejidades y complicaciones que plantea la calidad global del servicio habrán de ser tenidas en cuenta en el momento de elegir las medidas de calidad que han de ser incorporadas en los sistemas de incentivos que utilizan los reguladores para inducir a las empresas a que incorporen los objetivos de calidad en sus estrategias empresariales. Los estándares de calidad requieren establecimiento de normas que pueden ser difíciles de instituir en industrias donde el bien es heterogéneo y las preferencias del consumidor son poco conocidas.

La dificultad con la que en se encuentran los reguladores a la hora de elegir medidas adecuadas de la calidad basadas en resultados (outputs) ha llevado a utilizar medidas de calidad basada en imputs (por ejemplo, niveles de inversión mínimos).

En resumen, la calidad del servicio de las industrias de red es una variable multidimensional muy compleja, en la que con frecuencia es imposible observar de forma directa por parte de los consumidores y de medir por parte de los reguladores. De ahí que muchos de los estudios teóricos y empíricos que se llevan a cabo para conocer la evolución de la calidad en estas industrias se centren en unos pocos atributos o dimensiones, tales como la fiabilidad del servicio, los tiempos de ejecución a la hora de dar de alta un servicio y la atención al cliente (Sappington 2005). 


\section{Mecanismos para ajustar la calidad a las preferencias de los consumidores: mercado, autorregulación y regulación pública}

Por lo apuntado en el epígrafe anterior, se hace evidente que la calidad de los servicios de red se enfrenta a uno de los fallos de mercado mejor analizados por los economistas: la existencia de información asimétrica entre las dos partes que participan en una transacción. Por un lado, la empresa tiene más información que el consumidor acerca de las características técnicas del producto, así como sobre las razones que pueden afectar a la continuidad y fiabilidad del servicio. Por otro, a menudo la empresa, y los reguladores, desconocen con exactitud las preferencias y las valoraciones que hacen los consumidores sobre las diferentes dimensiones de la calidad, así como su disposición a pagar por ellas.

A su vez, los consumidores están en una situación de incapacidad para conocer -tanto a priori como a posteriori- la calidad real del servicio consumido. Las razones de esta incapacidad son de diferente naturaleza. Por un lado, es frecuente que en muchos de estos servicios los consumidores carezcan de las habilidades necesarias para distinguir entre la buena y la mala calidad. Por otro, acostumbran a tener limitaciones cognitivas para conocer los posibles riesgos y consecuencias para la salud y la vida del uso y consumo de estos bienes (agua, seguridad de los aviones, campos magnéticos, etc.).

Estas asimetrías en la información sobre los diferentes aspectos que forman la calidad global plantean problemas complejos y difíciles de abordar. Su existencia da lugar a dos tipos de fenómenos que afectan a la eficiencia asignativa de estos mercados. Uno, la incapacidad de los consumidores para observar la calidad del producto genera conductas de riesgo moral por parte de los oferentes. Y dos, esa misma incapacidad genera también conductas de selección adversa, en la medida en la disposición a pagar por parte de los consumidores se adecua al valor de lo que entienden que es la calidad «promedio» o esperada de las empresas que forman la industria. El resultado de estas conductas puede ser que los mercados tienden a no ofrecer servicios de alta calidad y que sólo los proveedores que ofrecen una calidad inferior al promedio acaben participando en esos mercados. Estas conductas no se producirían si tanto consumidores como oferentes pudiesen distinguir los servicios de buena y de mala calidad.

Tanto el análisis económico como la práctica empresarial y la de los reguladores han tratado de analizar la organización de la industria y los mecanismos que resultan más adecuados para lograr reducir el problema de la información asimétrica y sus consecuencias. Sin embargo, hay que hacer notar que en la literatura económica sobre organización industrial muestra una fuerte «asimetría» entre el interés por este tipo de mercados de servicios y el interés que tradicionalmente ha mostrado por los mercados competitivos.

Uno de los enfoques más atractivos y que ofrece más posibilidades para una mejor comprensión de las formas organizativas más adecuadas de estas industrias para resolver o disminuir este problema de información asimétrica ha venido de la frontera entre el análisis económico y el político. Se trata del conocido ensayo seminal de Albert O. Hirschman, «Exit, Voice, and Royalty. Responses to Decline in Firms, Organizations, and Status», publicado en 1970 (edición española de 1977). En este ensayo, Hirschman compara las virtudes e insuficiencias del mecanismo de «salida» (o «elegibilidad» en la terminología actual de las políticas de liberalización) a través de la competencia entre proveedores, con el mecanismo de «voz» utilizado por politólogos y sociólogos, mediante el cual consumidores y oferentes comparten información sobre la calidad de los bienes y sobre sus preferencias.

Este trabajo tiene relación con el conocido trabajo de Nelson (1970), publicado el mismo año, en el que este autor introdujo la conocida distinción entre «bienes de experiencia» y «bienes de búsqueda». En los primeros, los consumidores acaban conociendo la calidad de los productos a posteriori, a través del acto repetido de 
compra y uso o consumo del bien. En los segundos, los consumidores pueden conocer a priori la calidad de los bienes o servicios, pero sólo si se implican en un proceso de búsqueda que tiene costes.

Sin embargo, aunque nos es útil esta distinción entre tipos de bienes, hay que señalar que en ambos casos se trata de bienes cuya calidad acaba siendo verificable por el consumidor, ya sea ex ante o ex post. Sin embargo, algunos aspectos de la calidad de los servicios de las industrias de red no son verificables ni antes ni después del consumo, y se acercan en algún sentido a los llamados «bienes de confianza».

El enfoque de Hirschman, refinado por el propio autor en varios ensayos posteriores (Hirschman 1984), se ha mostrado muy creativo a la hora de identificar los bienes y servicios que debieran ser intensivos en el uso de la «voz»y no de la «salida». Mientras el mecanismo de salida parece mostrarse más eficaz que la voz en el caso de bienes en los que el consumidor conoce perfectamente lo que le gusta y es capaz de apreciar la calidad de los bienes o servicios que compra, la voz se muestra más eficaz que la salida a la hora de reducir la información asimétrica en el caso de bienes o servicios en los que existe una desproporción de conocimientos e información entre el vendedor y el comprador, o cuando el vendedor tiene dificultades para conocer las preferencias de los consumidores.

Uno de los trabajos de mayor interés para el tema que nos interesa es el de Young (1974). Este autor ha empleado el enfoque de salida y voz para el examen de una serie de servicios públicos urbanos (transporte, recogida de basuras o la televisión por cable). Sus conclusiones nos pueden ser útiles para los servicios de las industrias de red. Sugiere llevar a cabo un examen sistemático de tres procedimientos posibles para la organización y mejora de la eficiencia del funcionamiento de los servicios públicos: a) la evaluación sistemática del funcionamiento de las empresas; b) el uso de mecanismos de voz; y c) la salida por la competencia.

A partir de este enfoque, podemos identificar tres tipos de mecanismos a utilizar para ajustar la calidad de los servicios a las preferencias de los consumidores:

- Mecanismos de mercado («salida» o «elegibilidad» de los consumidores) a través de la competencia entre proveedores.

- Mecanismos de autorregulación de la calidad del servicio por parte de las propias empresas proveedoras.

- Regulación pública de la calidad.

Un resultado importante que se extrae tanto de los trabajos de Hirschman como de Young, y que interesa resaltar, es que estos mecanismos no son excluyentes, sino que en muchas ocasiones pueden ser combinados para mejorar los incentivos de las empresas. Dependerá de la naturaleza concreta del servicio que estemos considerando el elegir el «mix» adecuado de estos mecanismos.

\section{a) La opción de «salida» (o «elegibilidad» a través de la competencia entre proveedores)}

El análisis económico ha sugerido diferentes mecanismos para que sea el propio mercado el que resuelva el problema de la calidad en el caso de servicios en los que la calidad sea directamente verificable por los consumidores. Así, es posible que en el caso del transporte aéreo o de los servicios postales el consumidor tenga la posibilidad de conocer ex ante, mediante un proceso de búsqueda y comparación, cual es el proveedor que le ofrece un servicio de la calidad que desea. Y aun en el supuesto de que esta búsqueda no fuese posible o fuese costosa, podemos pensar que en la medida en que son servicios en los que se producen compras repetidas, el consumidor acabará conociendo la calidad que le ofrecen las diferentes empresas. 
Si esto es así, el mercado de estos servicios ofrece incentivos a consumidores y productores para resolver el problema de la calidad. En el primer caso, los oferentes tienen incentivos para mejorar la calidad dado que los consumidores puedan conocerla a priori. En el segundo caso, cuando el consumo reiterado de un servicio permite a los consumidores adquirir experiencia sobre su calidad, los oferentes tienen incentivos para ofrecer servicios de mayor calidad y tratar de construir una imagen de marca basada en la reputación de que esa empresa suministra un servicio de alta calidad. Las empresas pueden también optar por ofrecer un contrato mediante el cual garantiza al consumidor determinadas prestaciones y se hace responsable de los fallos que puedan producirse por negligencia o mala calidad del producto.

La literatura económica ha sugerido también otros mecanismos de mercado para ajustar la calidad a las preferencias. En general se orientan a señalizar la calidad mediante estrategias de precios, publicidad, diseño de atributos observables o garantías (Spulber 1989). El objetivo de todos estos mecanismos sería permitir a las empresas diferenciarse de sus competidores mediante la señalización de la mayor calidad de sus productos.

Sin embargo, hay evidencia analítica y empírica que sugiere que estos mecanismos no tienen mucho éxito. La crítica teórica señala que estos mecanismos de mercado pueden reducir el problema de la información asimétrica sobre la calidad, pero no la eliminan en la mayoría de los casos, especialmente en el de los servicios de mayor complejidad tecnológica, o en los que la seguridad e impacto medioambiental tiene más importancia. La razón de esta incapacidad está en que todos estos mecanismos exigen que los diferentes parámetros de la calidad sean verificables. Esto no sucede en un gran número de servicios que suministran las industrias de red. En algunos de los casos, como en el de la electricidad y ciertos servicios avanzados de telecomunicaciones, la naturaleza de los servicio tienen características que les asemejan más a los «bienes de confianza» que al de los bienes de experiencia o búsqueda. Y, tal como han señalado Emons (1997) y Gehrig y Jost (1995), en este tipo de bienes las formulas convencionales de protección al consumidor tienen una efectividad muy limitada, dado que las denuncias por negligencia o mala calidad son difícilmente demostrables.

La falta de eficacia de estos mecanismos de salida se demuestra también de forma empírica al observar el débil uso que han hecho los consumidores de la opción de salida (cambiar de suministrador) que les ha dado la liberalización. Por otro lado, un examen de los contratos del mercado libre del servicio eléctrico tanto en el Reino Unido, que es el mercado con mayor tradición liberalizadora, como en el mercado español muestra que las empresas prácticamente no han introducido en los contratos de los mercados libres niveles de calidad superiores, o garantías adicionales, más allá de la calidad promedio o de las garantías generales que están reguladas por los mercados a tarifa.

La conclusión es que en las industrias de red los mecanismos de mercado no son capaces de eliminar el problema de la información asimétrica, y que un eficaz fomento de la calidad y de la protección al consumidor debe ir más allá de lo que ellos pueden hacer por si mismos (Nuñez 2002).

\section{b) La autorregulación como mecanismo de voz}

Una opción alternativa o complementaria al mecanismo de salida («sino te gusta tu proveedor búscate otro») es el diseño e institucionalización de mecanismos de voz que permitan a los consumidores hacer llegar a las empresas sus preferencias y valoraciones sobre la calidad de los servicios que ofrecen; y a las empresas disponer de mecanismos que informen de sus compromisos de calidad con sus clientes. Estos mecanismos de voz institucionalizada pueden dar mayor información a las empresas sobre las razones del malestar de sus clientes y sus preferencias de la que ofrece la opción salida. 
En general, los economistas no se han mostrado muy interesados en analizar las posibilidades de este mecanismo alternativo al mercado. Pero además del trabajo ya mencionado de Hirschman, existen otros que nos ayudan a explorar esta opción para afrontar el problema de la información asimétrica en aquellas situaciones en las que existe un desequilibrio entre los conocimientos acerca de los bienes y servicios entre vendedor y comprador. Uno de ellos es un destacado trabajo de Arrow (1973) en el que ha analiza aquellos casos de productos tecnológicos complejos como las medicinas o los automóviles. Arrow subraya la importancia de la existencia de códigos éticos que «autoobliguen» a las empresas a aportar información relevante sobre los bienes, especialmente en situaciones donde sea conveniente que opere algún tipo de restricción a la conducta maximizadota de beneficios que puede ser socialmente indeseable por las consecuencias que esa conducta podría acarrear para la vida o la seguridad de las personas que utilizan esos bienes o servicios. Esta observación tiene plena validez para muchos de los servicios de las industrias de red aquí señaladas como por ejemplo el servicio eléctrico, el transporte aéreo y ferroviario o el suministro de agua.

Otro trabajo interesante en esta línea es el ya mencionado de Le Grand (2003). Este autor recomienda que las políticas públicas aumenten el poder de los clientes sobre los proveedores a través de diversos tipos de voz institucionalizada. Rechaza la idea de que los consumidores sean unos sujetos desamparados frente a las empresas. Y señala que las organizaciones en las que los usuarios o clientes están activamente representados son más eficientes y proveen un servicio de mejor calidad.

En las dos últimas décadas se han ensayado una gran diversidad de mecanismos de este tipo. Van desde los códigos de buenas prácticas, a la creación de figuras como la de Defensor del Cliente por parte de las empresas de servicios, o a la autoimposición de estándares de calidad auditados por organismos internos o externos a la industria. El objetivo de este tipo de mecanismos es mejorar la información entre empresa y consumidor y crear una reputación de empresa que provee de bienes y servicios de buena calidad. Una vez que existe, esta reputación constituye un activo económico importante para las empresas, que les permite maximizar sus beneficios. Por lo tanto, cabe esperar que esto genere incentivos para que las empresas emprendan este tipo de prácticas.

Este tipo de actuaciones se pueden incluir dentro de lo que genéricamente se llaman mecanismos de «autorregulación» de la calidad. Estos mecanismos pueden crearse a iniciativa de las propias empresas proveedoras o por parte de organismos colectivos o colegiados de la industria en la que operan las empresas. Su uso ha tenido ha tenido un gran desarrollo en los últimos años, especialmente en los países de cultura anglosajona. Inicialmente experimentados en las industrias de banca y servicios financieros, con la liberalización se han ido extendiendo en la última década a las industrias de servicios de red.

La autorregulación tiene algunas ventajas evidentes. Una de ellas es la poder aprovechar el conocimiento y la información de primera mano que las propias empresas autorreguladas tienen respecto de los atributos de los servicios que prestan, así como de las condiciones cambiantes del mercado y de la industria en la que desarrollan su actividad. Además, los costos de este mecanismo de autorregulación son afrontados directamente por las empresas.

Sin embargo, también tiene limitaciones muy claras, tal como ha puesto de manifiesto la literatura teórica (Nuñez 2001 y 2002). La razón básica de estas limitaciones es que la autorregulación constituye por definición una situación de captura regulatoria, donde el esquema de regulación es determinado por los incentivos e intereses del los mismos agentes regulados. En esta situación los incentivos de las empresas para aceptar voluntariamente ante sus clientes la existencia de negligencia o malas prácticas son cuando menos ambiguos. 
En cualquier caso, la literatura teórica no ha sido capaz de discernir con claridad cuál es el efecto sobre los clientes de la transparencia informativa de las empresas cuando informan de malas prácticas por parte de sus empleados. Si los clientes creyesen que la calidad promedio mejorará a partir del momento en que la empresa admita de que algunos de sus empleados no han cumplido los compromisos de calidad, entonces la autorregulación sería positiva para la empresa. Pero puede ocurrir también que una vez admitida por la empresa que no se han cumplido los estándares de calidad autorregulados en alguna circunstancia, esta información sea vista por los clientes como una confirmación de su idea de que la calidad promedio o esperada es baja. Los trabajos teóricos señalan que ambas conductas son racionales por parte de los consumidores.

La evidencia empírica que procede del conocimiento de la práctica interna de las empresas también es consistente con esta ambigüedad y falta de solidez en el tiempo de los incentivos de la autorregulación. La experiencia personal señala que los planes y estrategias de calidad de las empresas difícilmente resisten las malas coyunturas ligadas a factores diversos, como pueden ser las reorganizaciones, los estilos de dirección, las bonanzas económicas o los cambios en los incentivos de la regulación de precios.

\section{c) La regulación pública}

La alternativa a los mecanismos de salida por competencia y a la autorregulación es la regulación pública de la calidad. Esta regulación busca garantizar ciertos niveles o estándares mínimos de calidad del servicio suministrado por las empresas y, al mismo tiempo, ofrecer información a los consumidores sobre esos estándares.

La regulación puede estar basada en imputs -tales como requisitos de inversión mínima para desarrollar ciertas actividades -o en outputs- como la calidad de onda eléctrica o el tiempo máximo para atención de una reclamación, por ejemplo-. Los instrumentos típicos de la regulación pública en estas industrias son las certificaciones de calidad y el otorgamiento de licencias de actividad. Los incentivos más frecuentemente utilizados son las penalizaciones o multas para el caso de incumplimiento de los parámetros de calidad regulados, y de premios o bonos cuando la calidad del servicio de las empresas es superior a la regulada.

En los últimos años se observa una tendencia general en la mayoría de los países al aumento de la regulación pública de la calidad de las industrias de red. Esta tendencia es muy clara en el seno de la Unión Europea, tanto por parte de la Comisión como por el Parlamento Europeo, como en los países miembros. Uno de los caminos a través de los cuales puede observarse esta tendencia es la expansión de los contenidos de servicio universal (véase Anexo 1).

Este crecimiento de la regulación pública viene avalada por los resultados de muchos estudios teóricos y empíricos que sostienen que la mejora de la calidad en muchas de las actividades de las industrias de red se logra mejor a través de la regulación que del mercado. Así, para el caso de la distribución de electricidad Giannakis et al. (2003) han mostrado que la regulación es más eficiente. Entre las razones que mencionan está el hecho de que la distribución implica la producción de un bien de experiencia del que los consumidores puede que estén muy poco informados antes de consumirlo, que existen externalidades, como la polución ambiental y los riesgos para la salud y la seguridad para los que no utilizan la red y que la electricidad se suministra y consume a la vez, lo cual implica que no es probable que los consumidores reciban un servicio óptimo a nivel individual. Por eso, concluyen, para prevenir la asignación ineficiente de recursos en estas actividades deben incorporarse la regulación de la calidad a la regulación de esta industria. 
Un estudio más general sobre la regulación de la calidad de los servicios de las industrias de red es el llevado a cabo por Sappington (2005). A partir de una definición de calidad que toma en consideración sólo tres dimensiones (fiabilidad del servicio, plazos de ejecución y atención al cliente) revisa los estudios existentes tanto a nivel de mercado minorista como del mayorista. Entre otras razones por las que la calidad ofrecida puede ser inferior a la que maximiza el bienestar social señala el hecho de que las empresas que operan en industrias de red acostumbran a suministrar un nivel inferior al deseable socialmente, debido a que no pueden capturar todo el beneficio derivado de la calidad que suministran por el hecho de operar en redes donde existen otras empresas. Este argumento, entre otros, le llevan a defender la regulación pública.

La defensa de la regulación pública tiene no obstante el riesgo de hacer olvidar que esta opción tiene también limitaciones evidentes. Estas limitaciones han sido señaladas también por la literatura económica, tanto teórica como empírica. La principal, y a la vez la más evidente, es que el regulador comparte con el consumidor el mismo problema de la información asimétrica, auque pueda ser en menor cuantía. Por otro lado, el regulador comparte con el proveedor del servicio el desconocimiento de las preferencias de los consumidores por los servicios prestados y su disposición a pagar por servicios de mayor calidad.

A este problema hay que sumar el hecho de que en las industrias de red en la que diferentes operadores impactan sobre la calidad de las redes y del servicio que a través de ellas se prestan, el regulador tampoco puede discernir con claridad cuando la mala calidad del servicio tiene su origen en la negligencia en la operación de las redes o en las malas prácticas comerciales por parte del proveedor y cuando esa mala calidad tiene su origen en causas externas, factores de fuerza mayor, o en la acción de terceros sobre las redes.

Estas limitaciones de la regulación aconsejan, como se ha señalado con anterioridad, analizar en cada caso la opción o combinación más adecuada de los mecanismos de mercados, autorregulación y regulación pública. Pero ahora conviene explorar un poco más el uso de los instrumentos que maneja la regulación pública de la calidad.

\section{Mecanismos para regular la calidad}

A la vista de la imperfecta información que los consumidores tienen de la calidad del servicio de las industrias de red, y del defectuoso conocimiento que las empresas tienen de las preferencias de los clientes, los reguladores públicos se ven compelidos a diseñar sistemas de incentivos que fomenten la mejora de la calidad del servicio por parte de las empresas.

Existe una literatura teórica y empírica creciente orientada a analizar el impacto de las regulaciones por incentivos en las diferentes dimensiones o atributos de la calidad. Así, Ai y Sappinton (2005) han examinado el impacto de la regulación de calidad del servicio de telecomunicaciones en los EE.UU. Para ello toman en consideración cinco dimensiones de la calidad global: rapidez y fiabilidad de la instalación, quejas planteadas por los clientes, rapidez de resolución de problemas, alcance de las interrupciones y satisfacción de los clientes. A partir de la revisión de estudios recientes sobre como diferentes tipos de incentivos (price caps y earngis sharing) afectan a la calidad del servicio, los resultados revelan que bajo una regulación por incentivos no se observa ni un aumento ni una disminución significativa y sistemática de la calidad total, sino que algunas aspectos o dimensiones de la calidad aumentan mientras otros declinan.

Por su parte, Ajohi y Halvoort (2005) han examinado experiencias internacionales de regulación de la calidad en el sector de distribución de electricidad. Señalan que, en general, los reguladores están en posición de proporcionar a las empresas incentivos que promuevan mejoras incrementales en los sistemas de distribución, in- 
cluyendo aspectos como la calidad de onda de tensión, la fiabilidad de la red y la calidad comercial. Sin embargo, consideran que la tarea de los reguladores se complica debido a las limitaciones de información en que se mueven, tanto en términos de lo que es factible tecnológicamente como en lo referente al conocimiento que tienen de la valoración que hacen los consumidores. El resultado remite, por lo tanto, al difícil equilibrio que para las políticas públicas significa controlar los costes derivados de nuevas inversiones en infraestructuras y sistemas, por un lado y, por otro, promover la calidad.

Por su parte, Giannakis et al. (2003), han llevado a cabo un benchmarking de la regulación por incentivos de calidad entre las distribuidoras de electricidad del Reino Unido. Los resultados de su trabajo muestran como ha utilizado el regulador británico los diferentes incentivos (recompensas y sanciones marginales, multas y benckmarking) para regular la calidad en esa industria.

Para el caso del transporte ferroviario, Gibson (2005) ha analizado el caso de los incentivos de calidad establecidos en el Reino Unido para mejorar el servicio de Railtrack. Muestra como usuarios múltiples de la red (diferentes empresas de transporte ferroviario) y usos múltiples de esa red (transporte de pasajeros y de mercancías) pueden requerir que el regulador establezca diferentes tipos de fiabilidad del servicio. Sin embargo, resalta como un accidente que afecte a las percepciones públicas sobre la seguridad del servicio puede influir dramáticamente en la evaluación de la calidad del sector y en el clima regulatorio. Las conclusiones que extrae son de aplicación a otros sectores.

Para el sector del agua, un reciente estudio empírico de Lin (2005) utiliza una metodología de benchmarking para ilustrar como los objetivos de calidad pueden se incorporados a evaluaciones sistemáticas de las empresas suministradoras de agua. Con la utilización de una encuesta para empresas del Reino Unido y otros países en desarrollo, y utilizando una metodología estadística adecuada, muestra que para mejorar la calidad del servicio en los países es más conveniente añadir a las variables de output variables cualitativas (cobertura del servicio, test de cloro, continuidad del servicio) más que variables medioambientales.

En términos generales, este tipo de estudios teóricos y empíricos nos está diciendo que para incorporar los objetivos de calidad del servicio a los sistemas de incentivos de precios que utilizan los reguladores de las industrias de red se pueden seguir tres enfoques o aproximaciones:

- Evaluación sistemática del funcionamiento de las empresas y publicación de benchmarkings que pueden llegar a establecer clasificaciones de empresas según baremos de calidad.

- Regulación mediante de estándares de calidad mínima (de producto, técnicas y comerciales), que las empresas deben proporcionar a sus clientes para evitar sanciones financieras.

- Estándares de calidad basados en resultados, que incorporan sistemas de incentivos mediante distintos tipos de penalizaciones y de bonos.

Cada uno de estos enfoques tiene ventajas e inconvenientes que deben ser conocidos y valorados antes de su aplicación para evitar la aparición de incentivos inadecuados en los proveedores del servicio y en los consumidores. Un buen resumen puede verse en Holt (2005) y en Sappington (2004).

Un ejemplo de cómo están actuando los reguladores para incorporar objetivos de calidad mediante estándares garantizados y globales de calidad pueden verse en el caso del regulador de la industria eléctrica del Reino Unido, la OFGEM. Con la finalidad de mejorar los incentivos, en el último control de precios llevado a cabo en 2003, este re- 
gulador estableció una recompensa discrecional para fomentar la mejora de la calidad de servicio para los consumidores en aspectos o atributos de la calidad que no pueden ser fácilmente mesurables. Este esquema de recompensa discrecional está previsto que entre en vigor en abril/mayo de 2006 (OFGEM 2003b). El esquema de incentivos consiste en retribuir con un millón de libres las mejoras en tres dimensiones diferentes de la calidad: 1) Iniciativas que prioricen la calidad de la atención al cliente (600.000 libras); 2) Iniciativas que prioricen la calidad relacionada con la Responsabilidad Social Corporativa (RSC) (200.000 libras); y 3) Iniciativas dirigidas a mejorar las estrategias de calidad en las comunicaciones de las distribuidoras en sus relaciones con los clientes y con la sociedad (200.000 libras)

La OFGEM considera que la dimensión que más retos plantea y en la que hay más camino para la mejora es la atención al cliente. Para cada una de esas tres áreas establece unos requerimientos mínimos de calidad. Si las distribuidoras demuestran que sus iniciativas de mejora de la calidad cumplen con estos requisitos, recibirán una recompensa. El mecanismo diseñado por la OFGEM tiene el interés añadido de que la documentación que ha de aportar la empresa ha de incorporar la opinión de dos o tres organizaciones relevantes de stakebolders (organizaciones de consumidores o de la industria) como manera de implicarlos en la mejora de la calidad y validar la información aportada por la empresa y, a la vez, asegurar la integridad del mecanismo. Este es un ejemplo de cómo la mejora de la calidad puede involucrar a más de uno de los mecanismos (salida y voz) que hemos analizado anteriormente.

\section{Institucionalización de un esquema de evaluación de la calidad de las industrias de servicios públicos de red}

Al inicio de este trabajo se señaló que la calidad del servicio puede estar siendo el coste oculto de la liberalización y un aspecto desatendido en las primeras evaluaciones de los resultados de liberación en los mercados de industrias de red que ha ido realizando la Comisión Europea. El interés estaba centrado en ver los resultados sobre la competencia, la eficiencia y los precios.

Pero poco a poco, la calidad va entrando en las evaluaciones europeas. Hasta ahora el camino ha sido fundamentalmente a través de la expansión de las obligaciones de servicio que se han ido incluyendo en las directivas europeas de regulación sectorial de las industrias de electricidad, gas, telecomunicaciones, agua, transportes y servicios postales. Se podría decir que la expansión de las normas relacionadas con la calidad del servicio y de las percepciones de los consumidores está siendo el camino a través del cual se está reintroduciendo el concepto de industrias de servicios públicos de red, en vez del de industrias de servicios de interés general con el que la Comisión denominó a estas industrias a partir del inicio de la liberalización ${ }^{4}$.

La reintroducción del interés por la calidad del servicio y las percepciones de los consumidores sobre la liberalización tuvo lugar a partir del Eurobarómetro de 1997. En esta encuesta europea se incluyeron una serie de preguntas acerca de los «ciudadanos y la apertura a la competencia de los monopolios de servicio público». Los resultados llevaron a que a partir de ese momento se haya ido evaluando de manera periódica el grado de satisfacción de los clientes con las empresas de electricidad, gas, telefonía, agua, transportes y servicios postales en lo referente también a la calidad, la información, las normas contractuales y la atención al cliente.

Posteriormente, en junio de 2002, la Comisión publicó una «Nota metodológica para la evaluación horizontal de servicios de interés económico general» (Comisión Europea 2002). En ella justificaba la necesidad de evaluar

${ }^{4}$ En el Anexo 2 se resumen esas normas de calidad en las diferentes regulaciones sectoriales de estas industrias. 
no ya sólo en comprobar como estaba evolucionando la competencia, la eficiencia y los precios, sino también la calidad y las percepciones de los consumidores. Más concretamente, apuntaba la necesidad de evaluar para ver si los cambios introducidos por la liberalización se han percibido y valorado por parte de los clientes. Se señalaba que cualquier discrepancia entre la opinión de los usuarios y el funcionamiento de las industrias liberalizadas revelaría, a juicio de la Comisión la necesidad de aumentar la transparencia y mejorar la comunicación entre las partes afectadas. La Comisión establecía una serie de indicadores que sería deseable conocer para analizar de forma rigurosa la evolución de la calidad y las percepciones de los consumidores respecto de estos servicios (véase Anexo 2). Estableció además que esa metodología sería revisada en 2006. Es de esperar, por tanto, que en esa fecha las evaluaciones europeas se orienten en mayor medida a las cuestiones relacionadas con la calidad del servicio y se desarrolle una estructura institucionalizada de evaluación.

En este sentido, y de lo dicho hasta ahora, se puede concluir que el objetivo final de toda evaluación de la calidad es identificar y seleccionar un conjunto de medidas de la calidad global que reflejen adecuadamente las preferencias de los consumidores, que sean medibles y que puedan ser incorporadas a los sistemas de incentivos que utilizan los reguladores.

La bondad de la evaluación descansa de forma crucial sobre dos etapas de ese proceso. Por un lado, en la selección de las medidas para medir la calidad. Por otro, en el diseño de mecanismos adecuados que permitan incorporar esas medidas en el esquema de incentivos que utiliza el regulador.

Ambas tareas requieren, sin embargo, de la existencia de ciertas precondiciones, tales como la identificación de los objetivos que persigue la regulación pública, la ponderación y prioridad que los reguladores dan a cada uno de esos objetivos, la existencia de una buena coordinación entre todos los organismos implicados en los distintos aspectos de los servicios regulados o el conocimiento de las preferencias de los consumidores y disponer de información por parte de las empresas.

Como es obvio, esta no es una labor fácil y, de hecho, muy pocos reguladores se han enfrentado hasta ahora de forma sistemática a la misma. En cualquier caso, este objetivo requiere poner en marcha un proceso que integre de forma ordenada y coherente una serie de tareas, así crear una estructura institucionalizada las lleve a cabo de manera sistemática y ordenada.

Dos trabajos recientes ofrecen algunos criterios útiles para afrontar esta empresa. Uno es el de Sappington (2005), cuyas conclusiones sirven como guías para la evaluación de la calidad:

- Incluso bajo unas condiciones ideales, a la hora de implantar niveles adecuados de calidad del servicio, los reguladores necesitan información sustancial sobre las preferencias individuales y las tecnologías de producción de cada servicio. En la práctica este tipo de información no está disponible.

- Los instrumentos y las políticas de regulación basadas en estándares de calidad pueden tener efectos contraintuitivos a la hora de incentivar la provisión de un servicio de calidad.

- Los instrumentos y las políticas regulatorias que funcionan bien cuando la calidad del servicio es directamente observable o de poca importancia puede que no sirvan cuando la calidad del servicio es importante y no verificable.

- Una regulación óptima de la calidad puede implicar delegar significativamente en la empresa regulada (autorregulación).

- La regulación óptima de la calidad del servicio puede variar sustancialmente dependiendo de si afectan al servicio de comercialización o minorista (retail) o al servicio mayorista (wholesale), y en particular cuando el proveedor del servicio está verticalmente integrado. 
El otro trabajo es el de Holt (2005), de gran interés para identificar las tareas que tiene que desarrollar cualquier estructura orientada a la mejora de la calidad en los servicios de telecomunicaciones, electricidad y agua y, por extensión, al resto de industrias de red. Holt, después de defender la necesidad de montar una estructura institucionalizada de evaluación de la calidad del servicio, identifica doce etapas a través de las cuales transcurre el proceso de selección de medidas de calidad, su integración en el sistema de incentivos de precios que utiliza el regulador y la evaluación de los resultados de esas medidas. Esas etapas son las siguientes:

1. Definir los objetivos que persigue la regulación.

2. Ponderar esos objetivos y establecer las prioridades de la regulación.

3. Coordinar las responsabilidades de los diferentes organismos implicados.

4. Definir los estándares de calidad deseables para cada servicio.

5. Desarrollar las medidas de calidad del servicio.

6. Identificar un proceso para desarrollar esas medidas, a partir de la información de las empresas y de los consumidores.

7. Seleccionar el número de medidas que se van a utilizar para la evaluación.

8. Seleccionar los tipos de medidas.

9. Evaluar las medidas.

10. Comprender bien los sesgos y el contexto en que operan cada una de las medidas.

11. Determinar los incentivos adecuados para incorporar las medidas seleccionadas.

12. Implementar un proceso de control continuo y de revisión de proceso de evaluación.

En este trabajo se puede encontrar además una definición de las actividades comprendidas dentro de cada fase, de los problemas de todo tipo que hay que afrontar, de las virtudes y limitaciones de los distintos enfoques, así como ejemplos de cómo diferentes reguladores de telecomunicaciones, electricidad y agua están llevando a cabo esas tareas. Se trata pues una buena guía para la tarea que tienen delante todos aquellos que estén interesados en construir una estructura de mejora y evaluación de la calidad de estos servicios.

\section{Conclusión: La necesidad y conveniencia medir y evaluar la calidad}

Un proverbio inglés afirma que todo lo que se mide mejora, y que lo que no se mide empeora. Esta máxima es especialmente adecuada para defender la necesidad de medir la calidad del servicio de las industrias de red (telecomunicaciones, energía, agua, transportes y servicios postales) que han sido liberalizados en los últimos años en la mayoría de los países. La liberalización incorporaba una promesa de mejores precios y calidad de los servicios. Pero, en lo referente a la calidad existen motivos de duda para pensar que esa promesa se está cumpliendo. Posiblemente, la calidad del servicio puede estar siendo el coste oculto de la liberalización.

En este trabajo se han identificado las dificultades que enfrenta la tarea de mejorar la calidad. La mayor parte proceden del hecho de que la calidad es una variable multidimensional sobre la que se proyecta el problema de la información asimétrica entre proveedores y consumidores. Se han revisado además los diferentes enfoques que se utilizan para eliminar y reducir esa distinta información y para hacer que la calidad suministrada responda a las preferencias de los consumidores y a su disposición a pagar por los distintos servicios: salida a través de la competencia (elegibilidad), voz de los consumidores (autorregulación) y regulación pública. Los tres mecanismos tienen ventajas e inconvenientes, aun cuando la tendencia dominante es al uso de la regulación pública. 
Sin embargo, una conclusión que interesa resaltar es que esos tres enfoques no deberían ser vistos como excluyentes, sino como complementarios. Es especialmente importante que las políticas públicas aumenten el poder de los clientes sobre los proveedores a través del fortalecimiento de mecanismos de voz.

Por su parte, la revisión de los estudios, tanto teóricos como empíricos, de los mecanismos que pueden utilizar los reguladores para incorporar las medidas de calidad del servicio a los esquemas de incentivos de precios (competencia por comparación o benchmarkings, estándares de calidad mínima y estándares de resultados) muestran el difícil equilibrio en el que se han de mover las políticas regulatorias entre, por un lado, controlar los costes derivados de obligaciones de inversión y, por otro, promover la calidad. Pero todos ellos alientan a introducir objetivos de calidad de servicio en los sistemas de incentivos dirigidos a mejorar la eficiencia.

Para llevar a cabo esa tarea se requiere disponer de un procedimiento estructurado e institucionalizado que permita abordar de forma sistemática y coherente una serie de tareas necesarias para identificar las medidas más adecuadas para medir la calidad, para incorporar esas medidas al sistema de incentivos de precios y para evaluar sus resultados. Aunque la literatura ofrece criterios y guías de actuación útiles, esta es aún en gran parte una tarea pendiente en la mayor parte de los países.

Las ventajas de este esfuerzo son, no obstante, claras para todos los interesados (stakeholders) en la mejora de la calidad de estos servicios. Los reguladores estarán mejor informados a la hora de fijar objetivos de calidad y de definir e implementar los incentivos adecuados para que las empresas alcancen esos objetivos. Las empresas pueden de esa forma comparar su funcionamiento y resultados con los del resto de la industria, lo que les permite identificar debilidades relativas y buenas prácticas. Los consumidores pueden evaluar la calidad del servicio que reciben por parte de sus empresas proveedoras y cambiar de proveedor si no están satisfechos. Los policy-makers que han impulsado la liberalización y los responsables de gobiernos regionales y locales tendrán más información sobre la evolución de la calidad del servicio y de los caminos que pueden seguirse para mejorarla. Y a los investigadores académicos y especialistas en infraestructuras e industrias de red les ayudará identificar las vías de avance de las investigaciones centradas en la regulación de la calidad del servicio y los incentivos más adecuados para promoverla.

\section{REFERENCIAS BIBLIOGRÁFICAS Y DOCUMENTALES}

Chunrong, A. I. y Sappinton, D. (2005), «Reviewing the impact of incentive regulation on U. S. telephone service quality», Utilities Policy 13: 201-210.

Arrow, K. (1973), «Social Responsability and Economic Efficiency», Public Policy 21: 303-318.

Ajodhia, V. y Hakvoort, R. (2005), «Economic regulation of quality in electricity distributions networks», Utilities Policy 13: 211-221.

Baldwin, R. y Cave, M. (1999), Understanding regulation: theory, strategy, and practice. Nueva York: Oxford University Press.

CMT (1999), Informe a la Secretaría General de Comunicaciones sobre el proyecto por el que se regulan las condiciones de calidad en la prestación de los servicios de Telecomunicaciones, de 29 de julio.

Comisión Europea (2002), Nota metodológica para la evaluación horizontal de servicios de interés económico general. Comunicación de la Comisión al Consejo, al Parlamento Europeo y al Comité Económico y Social: COM/2002/0331 final.

- (2004), Resultados en el mercado de industrias de red que prestan servicios de interés general. Primera evaluación borizontal. Bruselas: Comisión Europea. 
- (2005), Fourth benchmarbing reporto on the implementation of the internal electricity and gas market. Bruselas: Comisión Europea.

Defensor del Cliente de Endesa (2004), Informe de actividades del primer ejercicio, http://www.endesa.es/Portal/es/gobierno_corporativo/junta_general_accionistas/ano_2005/Documentacion_2005.htm

Emons, W. (1997), «Credence Goods and Fraudulent Experts», Journal of Economics 28 (2): 107-119.

Giannakis, D. et al. (2003), «Benchmarking and incentive regulation of quality of service: an application to the UK electricity distribution utilities», Cambridge Working Papers in Economics 0408. Cambridge y Massachussets: The Cambridge-MIT Institute.

Gibson, S. (2005), «Incentivising operational performance on the UK rail infrastructure since 1996», Utilities Policy 13: 222-229.

Hirschman, A. O. (1977), Salida, voz y lealtad. Respuestas al deterioro de Empresas, Organizaciones y Estados. México: Fondo de Cultura Económica.

- (1984), De la Economía a la Política y más allá. México: Fondo de Cultura Económica.

Holt L. (2005), «Utility service quality. Telecommunications, electricity, water», Utilities Policy 13: 189-200.

Le Grand, J. (2003), Motivation, Agency and Public Policy: of Knights and Knaves, Pawns and Queens. Oxford: Oxford University Press.

Lin, Ch. (2005), «Service quality and prospects for benchmarking: Evidence from the Peru water sector», Utilities Policy 13: 230-239.

Nelson, P. (1970), «Information and Consumer Behauvior», Journal of Political Economy 78: 311-329.

Nuñez, J. (2001), «A simple model of self regulation», Economics Letters 74: 91-97.

- (2002), «¿Puede la autorregulación proteger contra el fraude y la negligencia?», Revista Perspectivas 6 (1). Santiago: Universidad de Chile.

OFGEM (2003a), Guaranteed and overall standars of performance, http://www.ofgem.gov.uk

- (2003b), Open letter on Ofgem's electricity distribution customer service reward scheme, bttp://www.ofgem.gov.uk

Sappington, E. M. (2005), «Regulating service quality: a survey», Journal of Regulatory Economics 27: 123-154.

Spulber, D. (1989), Regulation and Markets. Cambridge (Massachussets): MIT Press.

Young, D. (1974), «Exit and Voice in the Organization of Public Services», Social Science Information 13: 49-65.

Williams, G. (2002), Airlaine Comtetition: Deregulation's Mixed Legacy. Londres: Ashgatt. 
Resumen de las obligaciones de servicio público en el ámbito europeo

\begin{tabular}{|c|c|c|c|c|}
\hline & Regulación de precios & Regulación del acceso & Normativa de calidad & Otros objetivos \\
\hline $\begin{array}{l}\text { Electricidad } \\
\text { Generación de energía }\end{array}$ & & $\begin{array}{l}\text { La fuente de energía primaria debe } \\
\text { responder a las preocupaciones sobre la } \\
\text { seguridad del suministro. }\end{array}$ & $\begin{array}{l}\text { Seguridad del suministro, protección } \\
\text { de la salud pública. }\end{array}$ & $\begin{array}{l}\text { Consideraciones medioambientales } \\
\text { y de eficiencia energética. } \\
\text { Planificación a largo plazo. }\end{array}$ \\
\hline $\begin{array}{l}\text { Electricidad } \\
\text { Transmisión / } \\
\text { Distribución }\end{array}$ & & $\begin{array}{l}\text { Servicio universal. Los Estados miembros } \\
\text { se cerciorarán de que todos los } \\
\text { consumidores tienen derecho a electricidad } \\
\text { de una calidad determinada dentro de su } \\
\text { territorio a precios asequibles. }\end{array}$ & $\begin{array}{l}\text { Conexión garantizada a la red a todos los } \\
\text { ciudadanos, en condiciones razonables. } \\
\text { Criterios sobre servicios mínimos (por ej., } \\
\text { tiempo máximo antes de la reparación). }\end{array}$ & $\begin{array}{l}\text { Gestión de la sobrecarga. } \\
\text { Consideraciones ambientales. }\end{array}$ \\
\hline $\begin{array}{l}\text { Electricidad } \\
\text { Suministro }\end{array}$ & $\begin{array}{l}\text { Tarifas uniformes reguladas o aprobadas } \\
\text { para consumidores equivalentes. } \\
\text { Tarifas especiales para grupos de renta } \\
\text { baja. } \\
\text { Protección especial de los consumidores } \\
\text { vulnerables. }\end{array}$ & & $\begin{array}{l}\text { Protección contra la desconexión. } \\
\text { Derecho a devolución en caso de } \\
\text { interrupción del suministro. } \\
\text { Calidad mínima especificada. }\end{array}$ & $\begin{array}{l}\text { Transparencia de la información. } \\
\text { Medidas de protección del consumidor: } \\
\text { - transparencia } \\
\text { - condiciones contractuales, } \\
\text { - información clara sobre tarifas, } \\
\text { - amplia libertad para escoger el modo } \\
\text { de pago, } \\
\text { - procedimientos transparentes, sencillos } \\
\text { y poco onerosos para tramitar } \\
\text { reclamaciones. }\end{array}$ \\
\hline Gas & $\begin{array}{l}\text { Las autoridades nacionales de } \\
\text { reglamentación pueden fijar tarifas } \\
\text { reguladas o aprobadas a escala nacional. }\end{array}$ & No existe servicio universal obligatorio. & $\begin{array}{l}\text { - Seguridad del suministro. } \\
\text { - Regularidad del suministro. } \\
\text { - Calidad mínima especificada. } \\
\text { - Derecho a compensación o reembolso si } \\
\text { no se cumplen las normas de calidad } \\
\text { contratados. } \\
\text { - Tiempo de servicio. }\end{array}$ & $\begin{array}{l}\text { - Gestión de la sobrecarga por las } \\
\text { autoridades de reglamentación. } \\
\text { - Consideraciones ambientales. } \\
\text { - Planificación a largo plazo. } \\
\text { - Cohesión económica y social. } \\
\text { - Protección del consumidor (en especial, } \\
\text { de los consumidores vulnerables). }\end{array}$ \\
\hline
\end{tabular}


Resumen de las obligaciones de servicio público en el ámbito europeo

\begin{tabular}{|c|c|c|c|c|}
\hline & Regulación de precios & Regulación del acceso & Normativa de calidad & Otros objetivos \\
\hline Telecomunicaciones & $\begin{array}{l}\text { El precio de la obligación de servicio } \\
\text { universal ha de ser asequible. Por precio } \\
\text { asequible «se entiende un precio que los } \\
\text { Estados miembros definen en el ámbito } \\
\text { nacional teniendo en cuenta las } \\
\text { circunstancias nacionales espećficas, para } \\
\text { lo cual pueden recurrir al establecimiento } \\
\text { de tarifas comunes (...) o de tarifas } \\
\text { especiales dirigidas a cubrir las necesidades } \\
\text { de los usuarios con rentas bajas. } \\
\text { Deben existir tarifas especiales para los } \\
\text { consumidores menos favorecidos: } \\
\text { «garantizar el servicio universal puede } \\
\text { implicar la prestación de algunos servicios } \\
\text { a algunos usuarios finales a precios que } \\
\text { difieran de los resultantes de unas } \\
\text { condiciones de mercado normales». }\end{array}$ & $\begin{array}{l}\text { Todos los ciudadanos tienen derecho a los } \\
\text { servicios de acceso universal de una } \\
\text { calidad determinada a precios asequibles, } \\
\text { con independencia de su localización } \\
\text { geográfica. } \\
\text { Los Estados Miembros «podrán adoptar } \\
\text { medidas específicas para los consumidores } \\
\text { de las zonas rurales o geográficamente } \\
\text { aisladas para garantizarles el acceso a los } \\
\text { servicios (...) y que resulten asequibles } \\
\text { (...) en particular a los ancianos, } \\
\text { discapacitados y personas especialmente } \\
\text { necesitadas desde el punto de vista social. } \\
\text { Consulta de guía telefónica y número de } \\
\text { teléfonos públicos, sujeto al «derecho } \\
\text { de los abonados a la intimidad en lo que } \\
\text { respecta a la inclusión de información } \\
\text { personal en las guías disponibles». }\end{array}$ & $\begin{array}{l}\text { Son las «autoridades nacionales de } \\
\text { reglamentación» las que «podrán } \\
\text { especificar (...) los parámetros de calidad } \\
\text { (...) así como el contenido y formato de la } \\
\text { información que deberá hacerse pública». } \\
\text { La Directiva sugiere la aplicación de los } \\
\text { siguientes indicadores: } \\
\text { - Plazo de suministro de la conexión } \\
\text { inicial. } \\
\text { - Plazo de reparación de averías. } \\
\text { - Proporción de averías por línea de } \\
\text { acceso. } \\
\text { - Porcentaje de llamadas fallidas. } \\
\text { - Demora de establecimiento de llamada. } \\
\text { - Tiempo de respuesta para varios } \\
\text { servicios de la operadora. } \\
\text { - Porcentaje de cabinas telefónicas } \\
\text { en funcionamiento. } \\
\text { - Reclamaciones sobre facturación. }\end{array}$ & $\begin{array}{l}\text { Condiciones especiales para los } \\
\text { discapacitados, desconexión del } \\
\text { servicio y varios requisitos } \\
\text { de carácter social. } \\
\text { Protección del consumidor. }\end{array}$ \\
\hline $\begin{array}{l}\text { Servicios } \\
\text { postales }\end{array}$ & $\begin{array}{l}\text { Los precios de los servicios universales } \\
\text { han de ser asequibles, se han de } \\
\text { establecer en función de los costes } \\
\text { y deben ser transparentes y no } \\
\text { discriminatorios. }\end{array}$ & $\begin{array}{l}\text { Acceso universal: «oferta de servicios de } \\
\text { forma permanente en todos los puntos } \\
\text { del territorio». } \\
\text { Normas sobre la densidad de los puntos } \\
\text { de acceso. } \\
\text { Transparencia y no discriminación. }\end{array}$ & $\begin{array}{l}\text { Los Estados miembros se cerciorarán de que } \\
\text { sus normas de calidad sobre el servicio se } \\
\text { fijan y se publican, con objeto de garantizar } \\
\text { un servicio postal de buena calidad. } \\
\text { Los Estados miembros velarán por que el } \\
\text { proveedor/es garanticen «todos los días } \\
\text { laborables, y por lo menos } 5 \text { días por } \\
\text { semana, excepto en circunstancias o } \\
\text { condiciones geográficas excepcionales (...) } \\
\text { como mínimo: una recogida, un } \\
\text { adistribución al domicilio de cada persona } \\
\text { física o jurídica, etc. } \\
\text { Las normas de calidad irán evolucionando } \\
\text { en función del contexto técnico y social y } \\
\text { de las necesidades de los usuarios. }\end{array}$ & $\begin{array}{l}\text { Transparencia de la contabilidad. } \\
\text { Harmonización de las normas } \\
\text { técnicas. }\end{array}$ \\
\hline
\end{tabular}




\section{ANEXO 1 (Continuación)}

Resumen de las obligaciones de servicio público en el ámbito europeo

\begin{tabular}{|c|c|c|c|c|}
\hline & Regulación de precios & Regulación del acceso & Normativa de calidad & Otros objetivos \\
\hline $\begin{array}{l}\text { Transporte público } \\
\text { terrestre de pasajeros } \\
\text { (por ferrocarril, carretera } \\
\text { y vías navegables) }\end{array}$ & $\begin{array}{l}\text { El grado de transparencia de las tarifas } \\
\text { puede estar sujeto a regulación. }\end{array}$ & $\begin{array}{l}\text { No existe obligación de servicio universal. } \\
\text { Extensión de la red. } \\
\text { Servicios de transporte a zonas menos } \\
\text { pobladas. } \\
\text { Facilidad de acceso para personas con } \\
\text { movilidad reducida. }\end{array}$ & $\begin{array}{l}\text { - Frecuencia. } \\
\text { - Velocidad. } \\
\text { - Puntualidad. } \\
\text { - Fiabilidad. } \\
\text { - Información. } \\
\text { - Salud y seguridad de los pasajeros. } \\
\text { - Procedimientos de resolución de } \\
\text { controversias. }\end{array}$ & $\begin{array}{l}\text { - Impacto medioambiental. } \\
\text { - Cohesión regional. } \\
\text { - Integración entre diferentes transportes }\end{array}$ \\
\hline $\begin{array}{l}\text { Transporte } \\
\text { aéreo }\end{array}$ & $\begin{array}{l}\text { Libertad de precios, excepto en ciertas } \\
\text { rutas. }\end{array}$ & $\begin{array}{l}\text { El servicio público se limita a un número } \\
\text { muy reducido de rutas fijado en el } \\
\text { artículo } 4 \text { del Reglamento (CE) n. }{ }^{\circ} \\
2408 / 92 \text { y en el apartado } 2 \text { del artículo } \\
87 \text { del Tratado. }\end{array}$ & $\begin{array}{l}\text { Protección de los intereses de los } \\
\text { pasajeros de transporte aéreo. } \\
\text { Normativa de seguridad. } \\
\text { Regulación de la continuidad, la } \\
\text { regularidad y la capacidad de las rutas de } \\
\text { servicio público. }\end{array}$ & $\begin{array}{l}\text { Regulación relativa a las infraestructuras } \\
\text { aeroportuarias. } \\
\text { Regulación del tráfico aéreo. }\end{array}$ \\
\hline
\end{tabular}

Fuente: Elaboración propia a partir de las Directivas 2003/54/CE, 2003/55/CE, 2002/22/CE, 97/67/CE, 2002739/CE, de la COM (2000) 7 final y del Reglamento (CE) 2408/92. 
ANEXO 2

Indicadores que utilizan la UE para el análisis de los resultados de la liberalización de los servicios públicos

\begin{tabular}{|c|c|c|}
\hline Análisis del marco competitivo & Evaluación del funcionamiento del mercado en las industrias de red & Análisis de la percepción del consumidor \\
\hline $\begin{array}{l}\text { Estructura de mercado: } \\
\text { - Porcentaje de la demanda abierta legalmente y de hecho a la } \\
\text { competencia. } \\
\text { - Fecha de la apertura completa del mercado desde el punto } \\
\text { de vista legal. } \\
\text { - Designación del operador tradicional } \\
\text { - Número de competidores en el segmento. } \\
\text { - Porcentaje de la población que puede elegir entre más de x } \\
\text { proveedores en el segmento. } \\
\text { - Cuota de mercado del operador tradicional en el segmento. } \\
\text { - } \text { Internacientes de concentraciónalización de las empresas. } \\
\text { Estructura y regulación de la oferta: } \\
\text { - Grado de integración vertical del operador tradicional y de otros } \\
\text { competidores. } \\
\text { - Organismo regulador: identidad, competencias (derecho a imponer } \\
\text { decisiones, derecho a multar, etc.). } \\
\text { - Instalaciones críticas: identificación, tipo de acceso de terceros } \\
\text { (regulado frente a negociado), tipo de separación (contabilidad, } \\
\text { gestión, jurídica, propiedad). } \\
\text { Barreras de entrada: } \\
\text { - Cánones de acceso a la red para los competidores nacionales } \\
\text { - Interconexión expresada en porcentaje de la capacidad nacional. } \\
\text { - Eublicidad del exceso de capacidad disponible. } \\
\text { - Tiemportura y transparencia del mecanismo de tarificación. } \\
\text { - Porcentaje del suministro efectuado por acceso de terceros. } \\
\text { - Importaciones expresadas en porcentaje del consumo nacional. } \\
\text { Porcenta capacidad reservada por el operador tradicional }\end{array}$ & $\begin{array}{l}\text { En términos económicos y de empleo: } \\
\text { - Contribución del sector al PIB. } \\
\text { - Contribución del sector al empleo. } \\
\text { - Evolución del empleo en el operador tradicional. } \\
\text { - Evolución del empleo en el sector. } \\
\text { - Productividad del sector expresada en producción por persona } \\
\text { empleada. } \\
\text { - Productividad del operador tradicional expresada en producción } \\
\text { por persona empleada. } \\
\text { - Innovación del sector expresada en patentes y esfuerzo en I+D } \\
\text { En función del comportamiento de los precios: } \\
\text { - Evolución de los precios en moneda nacional en términos reales y } \\
\text { nominales. } \\
\text { - Precios relativos en euros respecto a la media de la UE. } \\
\text { - Asequibilidad: precio de los servicios en relación con la renta de } \\
\text { consumidores de renta baja/media (desglosados en consumidores con } \\
\text { distintos niveles de renta). } \\
\text { - Evaluación de la calidad de los servicios: } \\
\text { Fiabilidad de los servicios: } \\
\text { - Min/horas/días/semanas de interrupción de los servicios o de retraso } \\
\text { - en los mismos. } \\
\text { - Porcentaje de la población afectada por la interrupción de los servicios } \\
\text { o los retrasos en los mismos en un año. } \\
\text { - Tiempo de reparación tras las interrupciones del servicio o duración } \\
\text { - Tiempo de los plazos de reparación. } \\
\text { Accesibilidad: } \\
\text { - Número de oficinas de correos/número de buzones por habitante. }\end{array}$ & $\begin{array}{l}\text { - Satisfacción general, también respecto al precio } \\
\text { - y la calidad. } \\
\text { Problemas contractuales o de información entre } \\
\text { consumidores y prestadores del servicio. } \\
\text { - Indicadores de la resolución de conflictos. } \\
\text { - Dificultades para cambiar de empresa suministradora } \\
\text { de servicios. }\end{array}$ \\
\hline
\end{tabular}




\section{ANEXO 2 (Continuación)}

Indicadores que utilizan la UE para el análisis de los resultados de la liberalización de los servicios públicos

\begin{tabular}{|c|c|c|}
\hline Análisis del marco competitivo & Evaluación del funcionamiento del mercado en las industrias de red & Análisis de la percepción del consumidor \\
\hline $\begin{array}{l}\text { Estructura de la demanda: } \\
\text { - Crecimiento del sector en términos cuantitativos. } \\
\text { - Porcentaje de consumidores que han cambiado de proveedor al menos } \\
\text { una vez en el segmento abierto a la competencia en los últimos } \\
\text { tres años. } \\
\text { - Elasticidad precio de la demanda. }\end{array}$ & $\begin{array}{l}\text { - Número de plazas para pasajeros (trenes, líneas aéreas) por habitante. } \\
\text { - Acceso a servicios de distintas zonas geográficas. } \\
\text { Seguridad: } \\
\text { - Número de accidentes respecto a la distancia y/o los pasajeros. } \\
\text { - Indicadores de funcionamientos en materia de seguridad en el sector. } \\
\text { Repercusión en las disposiciones de obligaciones de servicio universal: } \\
\text { - Densidad y evolución de la red (p. ej., rutas de transporte aéreo } \\
\text { - Puevas o abandonadas). } \\
\text { en zonase de la población que no tiene acceso al servició (desglosado inferiores al nivel nacional). } \\
\text { Dimensión medioambiental: } \\
\text { - Porcentaje de fuentes de energía renovables respecto del consumo } \\
\text { total de electricidad, por fuente de energía. } \\
\text { - Porcentaje de fuentes de energía renovables respecto del total de } \\
\text { electricidad generada, por fuente de energía. } \\
\text { - Índices de consumo bruto de energía, por tipo de combustible, } \\
\text { incluyendo el gas. }\end{array}$ & \\
\hline
\end{tabular}

Fuente: Elaboración propia a partir de COM (2002) 331 final. 